\title{
The impact of assessing simulated bad news consultations on medical students' stress response and communication performance
}

\author{
Sandra van Dulmen ${ }^{a, *}$, Fred Tromp ${ }^{b}$, Frans Grosfeld ${ }^{c}$, \\ Olle ten Cate ${ }^{c}$, Jozien Bensing ${ }^{a, d}$
}

${ }^{a}$ NIVEL (Netherlands Institute for Health Services Research), P.O. Box 1568, 3500 BN Utrecht, The Netherlands

${ }^{\mathrm{b}}$ Department of Postgraduate Training for General Practice, Utrecht Medical Center St. Radboud,

P.O. Box 9120, 6500 HB Nijmegen, The Netherlands

'School of Medical Sciences, University Medical Center Utrecht, P.O. Box 85060, 3508 AB Utrecht, The Netherlands

${ }^{\mathrm{d}}$ Department of Health Psychology, Utrecht University, Heidelberglaan 1, 3584 CS Utrecht, The Netherlands

Received 2 February 2007; received in revised form 27 June 2007; accepted 27 June 2007

\section{KEYWORDS \\ Communication; \\ Medical students; \\ Salivary cortisol; \\ Simulated visits; \\ Stress}

\begin{abstract}
Summary
Seventy second-year medical students volunteered to participate in a study with the aim of evaluating the impact of the assessment of simulated bad news consultations on their physiological and psychological stress and communication performance. Measurements were taken of salivary cortisol, systolic and diastolic blood pressure, heart rate, state anxiety and global stress using a Visual Analogue Scale. The subjects were asked to take three salivary cortisol samples on the assessment day as well as on a quiet control day, and to take all other measures $5 \mathrm{~min}$ before and $10 \mathrm{~min}$ after conducting the bad news consultation. Consultations were videotaped and analyzed using the information-giving subscale of the Amsterdam Attitude and Communication Scale (AACS), the Roter Interaction Analysis System (RIAS), and the additional non-verbal measures, smiling, nodding and patient-directed gaze. MANOVA repeated measurements were used to test the difference between the cortisol measurements taken on the assessment and the control day. Linear regression analysis was used to determine the association between physiological and psychological stress measures and the students' communication performance. The analyses were restricted to the sample of 57 students who had complete data records. In anticipation of the communication assessment, cortisol levels remained elevated, indicating a heightened anticipatory stress response. After the assessment, the students' systolic blood pressure, heart rate, globally assessed stress level and state anxiety diminished. Pre-consultation stress did not appear to be related to the quality of the students' communication performance. Non-verbal communication could be
\end{abstract}

*Corresponding author. Tel.: +31 302729703; fax: +31 302729729.

E-mail address: s.vandulmen@nivel.nl (S. van Dulmen). 
predicted by pre-consultation physiological stress levels in the sense that patient-directed gaze occurred more often the higher the students' systolic blood pressure and heart rate. Post-consultation heart rate remained higher the more often the students had looked at the patient and the more information they had provided. However, the heart rate appeared to diminish the more often the students had reassured the patient. These findings suggest that in evaluating students' communication performance there is a need to take their stress levels into account.

(c) 2007 Elsevier Ltd. All rights reserved.

\section{Introduction}

Graduation from medical school in the Netherlands nowadays also requires mastery of an adequate level of communicative performance on the part of the student. The summative assessment of the related communication skills is increasingly becoming common practice for establishing the students' professional competence for the medical profession (de Haes et al., 2005). For that purpose, the medical students learn to cope with the demands of being confronted with all sorts of patient care and related questions, concerns and critical situations by practising communication skills in laboratory settings as part of the medical curriculum. In these settings, communication is taught using simulated patients who help prepare the young doctors to the stressors of real-life clinical practice. Already in the second year of medical school, the students have to conduct such a realistic medical consultation with a roleplaying, simulated patient. Apart from this stressful and demanding communicative task, the fact that their performance is being assessed at the same time inevitably influences students' stress level and communication behavior (Butterfield, 1988). A recent study indeed shows that performance pressure such as experienced during a formal assessment is related to momentary changes in physiological stress measures such as cortisol which could, in turn, influence communication performance negatively (Schlotz et al., 2006). The situation may even become more stressful when medical students have to perform difficult conversations such as bad news consultations, which specifically require mastery of psychosocial and affective communication skills. After all, delivering bad news and dealing with patients' emotions and psychological concerns have been recognized by physicians as the most challenging communication skills (Lee et al., 2002). So, as psychosocial talk seems the least internalized at the end of the medical school (Marvel et al., 2000), the discussion of psychosocial topics is expected to suffer most under increased tension. And even if the students' competence is sufficient, their performance may show deficiencies due to the stress related to being assessed. Insight into the stress reactions undergraduates display the first time they are confronted with the challenges and assessment of stressful communication, may contribute to understanding and appraising actual performance. In addition, as medical students do not seem to improve and sometimes even deteriorate in their communication behavior the further they advance in their training (Wahlqvist et al., 2005), unraveling existing stress-communication relationships early in the curriculum may help to find ways to make ongoing communication training more effective by taking into account the knowledge about these potentially disturbing interactions.

The present study was set up to find out how stressprovoking first-time simulated bad news consultations are for second-year medical students and how the experienced stress is related to the students' communication performance. More specifically, the following questions were addressed:

1. How does - the anticipation of - a formal assessment of bad news communication performance influence medical students' physiological and psychological stress levels?

2. How do medical students communicate verbally and nonverbally with standardized patients in a simulated bad news consultation?

3. What is the relationship between the way medical students communicate with standardized patients during a simulated bad news consultation and their physiologically and psychologically measured stress levels?

We expected that the anticipation of the assessment of the communication performance would increase stress levels in comparison to the stress levels measured on a relatively quiet day without assessment. More specifically, a heightened cortisol reaction was expected because of the possible stressful character of the interview. After the assessment, stress levels were expected to have normalized again. With respect to communication performance, in conformity with the positive effects of a warm contact found earlier (Grewen et al., 2003), psychosocial and affective verbal and non-verbal communication behavior was expected to be associated with less stress responses. Associations may, however, depend on the way the communication is rated as either descriptive or normative.

\section{Methods}

\subsection{Design of the study}

As part of the regular medical curriculum of the University Medical Center Utrecht in the Netherlands, the medical students have to conduct a bad news consultation with a standardized patient for the first time in their second year. The consultations are recorded on videotape. The simulated patient judges the student's performance together with a second student who is also present during the consultation. For the purpose of this study, started in 2003, the students were asked to complete a pre- and a post-consultation questionnaire on psychological stress and to measure their 
physiological stress levels, including cortisol, systolic and diastolic blood pressure and heart rate, at different moments in time. The students who agreed to participate signed a consent form. For this study, the Medical Ethical Committee of the University Medical Center Utrecht considered the adherence to privacy regulations for using the collected data sufficient to safeguard ethical consent. After having received all measurements in order, every student received a financial incentive.

\subsection{Assessment of stress responses}

Momentary psychological or self-reported stress was assessed using the State-Trait Anxiety Inventory (STAI) and a Visual Analogue Scale (VAS) for a more global assessment of psychological stress. Using the STAI, a well-known instrument with sound psychometric qualities, state anxiety was measured with 20 four-point Likert Scale items (Spielberger, 1983). Total scores range from 20 to 80 . A score about 34 is considered normal, 48 an acute anxiety response to a stressful situation. The state anxiety scale was completed $5 \mathrm{~min}$ before (pre-consultation measurement) and $10 \mathrm{~min}$ after the simulated bad news consultation (post-consultation measurement). The VAS was used as a $10 \mathrm{~cm}$ line ranging from 'no stress' to 'a lot of stress' and completed pre- and post-consultation as well.

Physiological stress was assessed by taking measures of the students' heart rate (hr), blood pressure (bp) and salivary cortisol. Heart rate, systolic and diastolic blood pressure were measured using a portable writs monitor, at the same moments as the students' completed the questions on psychological stress. The students' saliva was taken to measure cortisol levels. The concentration of cortisol in saliva is known to reflect blood levels (Kirschbaum and Hellhammer, 1994). Cortisol shows a well-documented circadian rhythm with peak levels observed shortly after awakening and steadily decreasing values thereafter (Wust et al., 2000). Enhanced secretion is seen as a leveled curve in people reporting chronic anxiety and social stress (Wust et al., 2000). When using cortisol levels as indicator of heightened stress, measurements should therefore be taken more than once (Hellhammer et al., 2007), preferably at the same time points on a stressful as well as a quiet day. Figure 1 shows the cortisol protocol followed by the students. The students were instructed to take the samples at the same time on the assessment and the control day and to register each sampling time. The measurements on the quiet day functioned as personal control measurements.
In that way, it was possible to compare individual cortisol levels with each student's own baseline level and fluctuations. A salivette was used to sample saliva. The students chewed a cotton roll for $1 \mathrm{~min}$ to obtain a sample. The samples were stored in a freezer. When all samples were taken, the salivettes were sent for analysis to the laboratory of Professor Kirschbaum in Dresden.

\subsection{Assessment of communication performance}

The medical students' communication performance was observed on the videotapes by an experienced observer (FT) using different observation systems, including the Amsterdam Attitude and Communication Scale (AACS), the Roter Interaction Analysis System (RIAS) and global affect scores. In addition, several non-verbal communication behaviors were rated.

The adapted information-giving subscale of the AACS (Ten Cate and De Haes, 2000; De Haes et al., 2001, 2005) was used to get an impression of which specific communication behaviors the student performed more or less adequately. For the purpose of this study, the following communication categories were rated: (1) structuring the communication; (2) information-giving skills; (3) using the appropriate conversation model; (4) using the bad news conversation model; (5) using the participation model; (6) handling emotions (De Haes et al., 2001, 2005). In the AACS, the communication performance of the students gets a normative rating using a five-point Likert Scale from 'bad' to 'good'. The AACS has been shown to be psychometrically sound (De Haes et al., 2001).

The RIAS (Bensing, 1991; Roter, 2002) was used to count every communication behavior the student uses when talking to the simulated patient. The RIAS observation system distinguishes instrumental (task-focused) and affective (socio-emotional) verbal behavior reflecting the curecare dimension. The unit of analysis is the utterance or smallest meaningful string of words. Utterances are assigned to mutually exclusive categories. The RIAS has proven validity and reliability (Roter and Larson, 2002). For the purpose of this study, the instrumental RIAS codes were aggregated into composite summary measures including medical question-asking; question-asking about psychosocial issues, lifestyle issues or feelings; medical informationgiving; and psychosocial information-giving. The expressions of concerns, reassurances, empathy and paraphrases were coded as the most relevant affective communication categories. Contrary to the AACS, no normative codes are
ASSESSMENT DAY

(simulated bad news consultation)

CONTROL DAY

(within 10 days after assessment day)

\section{Salivette nr. When?}

Directly after awakening

$5 \mathrm{~min}$. before consultation (pre-test)

$10 \mathrm{~min}$. after consultation (post-test)

Salivette nr. When?

Same time as 1

Same time as 2

Same time as 3

One hour before no food, coffee, alcohol or teeth brushing

Figure 1 Protocol for obtaining saliva. 
attributed to the communication behaviors coded with the RIAS. In addition to the verbal coding, the student's global affect scores, measuring dominant, friendly, concerned and involved behavior, were assessed with six-point Likert items (Roter, 2002).

Non-verbal communication was rated by counting the prevalence of smiling, nodding and patient-directed eye gaze on the part of the medical student. Non-verbal communication is considered especially relevant for the affective and psychosocial context of care (Bensing et al., 1995; Roter et al., 2006).

\subsection{Analysis}

Differences between the multiple cortisol measurements on the assessment and the control day were tested using MANOVA repeated measurements. MANOVA was used instead of a repeated measurements ANOVA, because the variances for the measurement moments were not equal and neither were the correlations between these moments. In the MANOVA approach, a fully unstructured variance-covariance matrix for the measurement moments is modeled together with a mean for every measurement moment. Our hypothesis that the same measurement moments on day 1 differed from the same moment on day 2 was tested with a Wald contrast test resulting in a chi-square value (Hedeker and Gibbons, 2006). Analysis was done using MLwiN2.02. Prepost differences between the other stress measurements with paired-samples $t$-test. Associations between psychological and physiological stress scores and ratings of clinical communication were studied using linear regression analysis with (1) communication variables, i.e., AACS and RIAS categories, global affect scores and non-verbal behaviors, as dependent variables and the six pre-consultation stress measures as independent variables; and (2) post-visit stress measures as dependent variables and the same communication variables as independent variables. As there appear to be large gender differences in reactivity to stress (Steptoe et al., 1996; Wust et al., 2000; Kudielka and Kirschbaum, 2005) as well as in the use of affective communication behaviors (Meeuwesen et al., 2002; Van den Brink-Muinen et al., 2002) gender was controlled for in the MANOVA as well as the linear regression analyses. The analyses were performed using SPSS ${ }^{\circledR}$ version 14.0 (Statistical Package for the Social Sciences), Chicago, IL, USA.

\section{Results}

\subsection{Study sample}

The second-year medical students cohort included 237 students, 65 men (27\%) and 172 women (73\%). Seventy of them agreed to participate. Their simulated consultations took place within 1-month time. From these students, 414 salivettes were obtained of which 403 were suitable for analysis. In 57 of the 70 students (48 female and 9 male), complete data records were obtained for analysis.

\subsection{Anticipation, assessment and stress}

As Figure 2 shows, no difference was found in the students' awakening cortisol level between assessment and control day. Just before the assessment, the students' cortisol level appeared to be significantly elevated compared to the same point in time on the quiet control day (chi-square 7.17, $p<.01)$. After the assessment, the cortisol level still appeared to be elevated compared to the level on the control day (chi-square 6.09, $p<.05$ ). In addition, as expected given the slope of the normal curve, the cortisol measurements taken during the day are more strongly interrelated than the awakening and day-time measurement (Table 1).

Figure 3 shows that, at post-consultation, the students' systolic blood pressure, heart rate, globally assessed stress level and anxiety level had significantly decreased compared to the pre-consultation measurement. No pre-post difference was found in diastolic blood pressure and cortisol levels.

Before the consultation, significant positive relationships were found between, on the one hand, the students' VAS score and, on the other, their heart rate $(r=.31, p=.02)$ and state anxiety level $(r=.68, p<.001)$. The students' systolic and diastolic blood pressure correlated highly $(r=.71, p<.001)$. Moreover, heart rate was positively correlated with state anxiety $(r=.32, p=.02)$ and systolic blood pressure $(r=.29, p=.03)$. At post-consultation, a positive relationship was also found between the VAS score

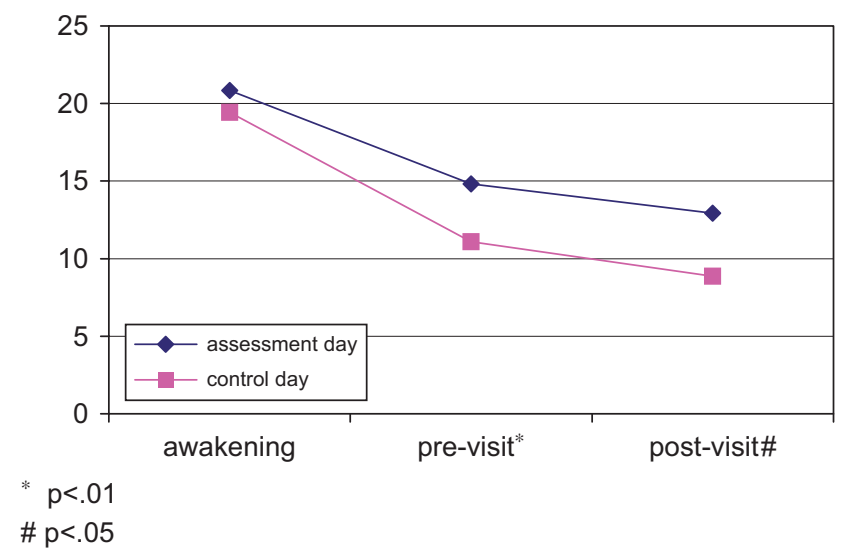

Figure 2 Mean cortisol levels at different time points (MANOVA repeated measurements).

Table 1 Relationships between different cortisol measurements in Pearson correlation coefficients.

\begin{tabular}{|c|c|c|c|c|c|}
\hline \multicolumn{3}{|c|}{ Assessment day } & \multicolumn{3}{|c|}{ Control day } \\
\hline 1 & 2 & 3 & 4 & & 6 \\
\hline Awakening & Pre-visit & Post-visit & Time 1 & Time 2 & Time 3 \\
\hline \multicolumn{6}{|l|}{1} \\
\hline \multicolumn{6}{|l|}{2.16} \\
\hline $3.31^{*}$ & $.61^{*}$ & & & & \\
\hline $4.41^{*}$ & $.23^{*}$ & $.31^{*}$ & & & \\
\hline $5.24^{*}$ & $.50^{*}$ & $.49^{*}$ & $.46^{*}$ & & \\
\hline 6.07 & $.23^{*}$ & $.31 *$ & $.36^{*}$ & $.64^{*}$ & \\
\hline
\end{tabular}




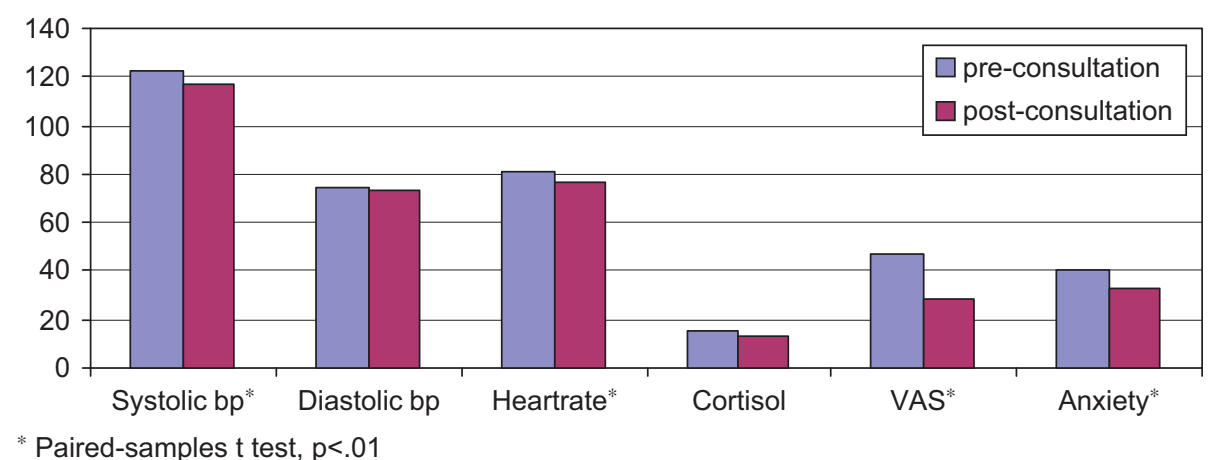

Figure 3 Pre- and post-consultation physiological and psychological stress levels.

Table 2 Frequencies of communication composites used by the medical students.

\begin{tabular}{lcc}
\hline RIAS composites & \multicolumn{1}{l}{ Medical students } \\
\cline { 2 - 3 } & Mean (S.D.) & Range \\
\hline Instrumental communication (sum score) & $57.1(21.3)$ & $16-115$ \\
$\quad$ Medical question-asking & $1.3(1.2)$ & $0-5$ \\
Medical information-giving & $46.5(18.9)$ & $3-95$ \\
Psychosocial question-asking & $4.4(2.9)$ & $0-11$ \\
Psychosocial information-giving & $4.8(4.1)$ & $0-17$ \\
Affective communication (sum score) & $13.3(5.3)$ & $2-32$ \\
Concerns & $1.6(1.5)$ & $0-7$ \\
Reassurances & $0.6(0.9)$ & $0-3$ \\
Empathy & $4.6(2.9)$ & $0-14$ \\
Paraphrases & $6.5(3.6)$ & $1-16$ \\
\hline
\end{tabular}

and state anxiety $(r=.35, p=.01)$, between heart rate and diastolic blood pressure $(r=.26, p=.05)$ and, again, between systolic and diastolic blood pressure $(r=.70$, $p<.001)$.

\subsection{Communication with standardized patients}

The ratings on the different AACS items varied between insufficient and good on all items, with significantly $(p<.01)$ higher mean scores on information-giving skills (mean 3.54, S.D. .54) than on handling emotions (mean 3.34, S.D. .55), structuring (mean 3.30, S.D. .54) and using the participation model (mean 3.30, S.D. .57).

In Table 2, the frequencies of the specific RIAS composites under study are shown. Overall, in comparison with affective communication-which can also be conveyed non-verbally - the students appeared to use instrumental communication more than four times more often. To be more specific, during the simulated visits, the medical students were primarily occupied with providing medical information. The few questions they asked more often concerned psychosocial than medical issues.

Table 3 shows that higher overall scores on the AACS could primarily be ascribed to students using psychosocial information-giving skills. The positive relationship between handling emotions and instrumental communication indicates that, apart from students' affective communication, the exchange of medical and psychosocial information can also be understood as a way to handle patients' emotions. Further, every AACS item appeared to be significantly positively related to the students' behavior of being friendly, concerned and involved (see Table 3).

\subsection{Communication and physiological and psychological stress}

No significant relationships were found between the students' physiological and psychological measured stress before the consultation and the quality of their communication measured with the AACS. The students appeared to express more paraphrases (RIAS), the higher their preconsultation systolic blood pressure and the lower their preconsultation cortisol level $(\beta=.40, p=.04$ and $\beta=-.26$, $p=.05$, respectively). The students looked at the simulated patient more frequently, the higher their systolic blood pressure and heart rate before the consultation $(\beta=.56$, $p=.004$ and $\beta=.30, p=.04$, respectively) and the lower their pre-consultation diastolic blood pressure $(\beta=-.42$, $p=.02$ ). In addition, the students showed a tendency towards gazing at the patient more frequently as well as showing more involvement in the patient (global affect score) and expressing concerns more often, the lower their psychological stress level (VAS score) before the 
Table 3 Correlations between the students' RIAS and AACS scores.

\begin{tabular}{|c|c|c|c|c|c|c|c|}
\hline \multirow[t]{2}{*}{ RIAS constructs } & \multicolumn{7}{|l|}{ AACS } \\
\hline & Structurin & $\begin{array}{l}\text { ng Information- } \\
\text { giving }\end{array}$ & $\begin{array}{l}\text { Appropriate } \\
\text { model }\end{array}$ & $\begin{array}{l}\text { Bad news } \\
\text { model }\end{array}$ & $\begin{array}{l}\text { Participation } \\
\text { model }\end{array}$ & $\begin{array}{l}\text { Handling } \\
\text { emotions }\end{array}$ & $\begin{array}{l}\text { Overall } \\
\text { scores }\end{array}$ \\
\hline $\begin{array}{l}\text { Instrumental communication } \\
\text { (sum score) }\end{array}$ & .21 & $.37^{* *}$ & .06 & .17 & .19 & $.28^{*}$ & .26 \\
\hline Medical questions & -.01 & -.13 & $-.37^{* *}$ & -.23 & .09 & .08 & -.04 \\
\hline Medical information & .24 & $.33^{*}$ & .02 & .11 & .15 & .25 & .21 \\
\hline Psychosocial questions & -.07 & .18 & .10 & .19 & $.29^{*}$ & .20 & .16 \\
\hline Psychosocial information & .05 & $.32^{*}$ & .26 & $.33^{*}$ & .06 & .13 & $.29^{*}$ \\
\hline $\begin{array}{l}\text { Affective communication } \\
\text { (sum score) }\end{array}$ & .26 & .18 & .17 & .23 & .18 & $.34^{*}$ & .20 \\
\hline Concerns & .13 & .17 & .14 & .22 & .23 & .25 & .22 \\
\hline Reassurances & .06 & .07 & .09 & .20 & .09 & .05 & .12 \\
\hline Empathy & -.01 & $.30^{*}$ & .09 & .18 & .15 & $.39^{* *}$ & .25 \\
\hline Paraphrases & $.32^{*}$ & -.06 & .09 & .04 & .02 & .07 & -.03 \\
\hline \multicolumn{8}{|l|}{ Affect scores } \\
\hline Dominant & .06 & $.33^{*}$ & .20 & .19 & $.27^{*}$ & .15 & .21 \\
\hline Friendly & $.29^{*}$ & $.52^{* *}$ & $.34^{* *}$ & $.46^{* *}$ & $.34^{*}$ & $.56^{* *}$ & $.64^{* *}$ \\
\hline Concerned & $.32^{*}$ & $.49^{* *}$ & $.42^{* *}$ & $.54^{* *}$ & $.30^{*}$ & $.56^{* *}$ & $.66^{* *}$ \\
\hline Involved & $.48^{* *}$ & $.54^{* *}$ & $.34^{*}$ & $.43^{* *}$ & $.45^{* *}$ & $.50 * *$ & $.65^{* *}$ \\
\hline
\end{tabular}

consultation $(\beta=-.34, p=.06 ; \beta=-.38, p=.06$; and $\beta=-.36, p=.07$, respectively).

After the consultation, the students' heart rate was higher the more medical information they had provided $(\beta=2.60, p=.01)$ and the more frequently they had gazed at the patient during the consultation $(\beta=2.27, p=.03)$. Heart rate appeared to be lower the more often the students had reassured the patient $(\beta=-2.10, p=.04)$. In addition, the students' globally assessed stress level appeared to be lower at post-consultation, the more concerns they had expressed $(\beta=-2.47, p=.02)$ and tended to be lower the better the students had performed overall, measured with the AACS, and the less empathy (RIAS) they had shown $(\beta=-1.82, p=.08$ and $\beta=1.86$, $p=.07)$. No significant relationships were found between the students' communication performance and any of the other stress measures.

\section{Discussion}

The present study examined to what extent simulated bad news consultations are stress-provoking for second-year medical students. The leveled daily cortisol curve on the assessment day indicates that the mere anticipation of an assessment of a bad news delivery increases the students' cortisol response in comparison with the measurements on a quiet day without assessment. In addition, whereas this cortisol response did not decrease during interviewing, other interrelated stress measures, including systolic blood pressure, heart rate, globally assessed stress and state anxiety, appeared to diminish clearly. The analysis of the students' verbal communication behavior reveals that they communicate more in an instrumental than an affective way, mainly by providing medical information. Stress measured before the simulated consultation does not appear to have relevance for the quality of the communicative performance during the interviewing. So, contrary to the classical theory from Yerkes and Dodson (1908) which describes the relationship between stress and performance as a U-curve turned upside down, the students in our study do not perform better nor worse when they feel more stressed right before having to perform a simulated bad news consultation. This may be indicative of a ceiling effect with not enough variation to detect mutual relationships. The frequency in which the students employed patient-directed gaze did seem to be associated with stress levels measured before the consultation, suggesting that a certain level of physiological arousal is necessary to make this highly relevant type of communication behavior possible.

The type of communication used seems to be related to the students' stress levels measured after the consultation; the amount of medical information and patient-directed gaze both increased the students' heart rate, suggesting that eye contact could be indicative for being alert. But, the more often the students communicated in an affective way by expressing reassurances or concerns, the lower their stress response measured after the consultation. These results point to the existence of different operating mechanisms: one explaining the stress-provoking character of looking at a patient, the other explaining the stresslowering character of communicating in an affective way. $A$ relationship between non-verbal communication and 
stress response was previously shown in deaf people signing (Malinow et al., 1986), indicating that the mere cognitive act of information-processing and evaluation through making eye contact brings about a physiological response, i.e., being alert. The stress-provoking character of patientdirected gaze has to be explored further, for instance by letting the students look back at their own videorecorded consultations and asking them to reflect on their experienced emotions and intentions when gazing at the patient. The different stress responses in terms of systolic and diastolic blood pressure have been shown before (Phillips et al., 2005).

Overall, the results show that the medical students spend the majority of the time during the simulated patient consultations on giving medical information. This is in conformity with a study conducted decades ago (Batenburg and Gerritsma, 1983), that showed that medical students perform better in information-giving skills than in handling emotions, which may reflect the students' need to express their knowledge. Alternatively, it may compensate their restricted ability to cope with patients' strong emotions. A recent study in general practice showed that in real-life everyday visits experienced doctors ask more medical questions and provide half as many units of information. No difference was found in the number of times psychosocial issues were discussed (Van den Brink-Muinen et al., 2004).

In our study, the relationships between AACS and RIAS scores suggest that mainly asking medical questions (RIAS) may be indicative of using a wrong conversation model, whereas the quality of information-giving as measured by the AACS is judged to be higher when the information is provided in an empathic, involved and friendly way. In addition, the bad news model is judged to be used more appropriately, the more psychosocial information the medical students gave. Finally, the medical students' ability to paraphrase seems indicative of applying better structuring skills, which does not come as a surprise, since paraphrasing is a way of structuring the communication process.

In the present study, the stress responses measured at different levels of consciousness, psychological stress as conscious and physiological stress as unconscious measurement, seem to be interrelated. However, each level shows different relationships with different elements of the communication performance measured in this study. These findings suggest that in evaluating students' communication performance there is a need to take their stress levels into account.

At Utrecht Medical Center, students perform simulated bad news consultations in their second year of medical education. Without disturbing this routine, the students were asked to participate in our study on the relationship between stress and communication. They were not aware of the variables under study nor of the relationships we expected to find. Given the burden of the assessment even without our interference, we were happy to be able to recruit 70 students. An advantage of this study was that it was set within the usual curriculum, and business was continued as usual. However, given the character of the study, we cannot tell what element heightened anticipatory stress levels most: the assessment itself, the fact that the students had to deliver bad news, or that they had to perform on a certain quality level. More research is needed to compare, for instance, the impact of difficult and easy conversations or of conversations with and without a formal assessment. For all students, the bad news consultation was the first experience of a communication assessment. In view of cortisol responses this is important, because repeated exposure to stress in novices may lead to adaptation and less cortisol response. So, the in the present study found anticipatory stress response reflected in heightened cortisol levels is expected to diminish when students advance through medical school. Longitudinal studies are needed to confirm this.

\section{Role of funding sources}

The study was supported by a grant from the Research Institute Psychology \& Health. The Research Institute had no further role in study design; in the collection, analysis and interpretation of data; in the writing of the report; and in the decision to submit the paper for publication.

\section{Conflicts of interest}

All authors declare that they have no conflicts of interest.

\section{Acknowledgment}

This study was possible, thanks to the participation of the medical students.

\section{References}

Batenburg, V., Gerritsma, J.G., 1983. Medical interviewing: initial student problems. Med. Educ. 17, 235-239.

Bensing, J.M., 1991. Doctor-patient communication and the quality of care. An observation study into affective and instrumental behaviour in general practice. Thesis, Utrecht/Rotterdam, NIVEL/EUR.

Bensing, J.M., Kerssens, J.J., Van der Pasch, M., 1995. Patientdirected gaze as a tool for discovering and handling psychosocial problems in general practice. J. Nonverbal Behav. 19, 223-242.

Butterfield, P., 1988. The stress of residency: a review of the literature. Arch. Intern. Med. 148, 1428-1435.

De Haes, J.C., Oort, F., Oosterveld, P., Ten Cate, O., 2001. Assessment of medical students' communicative behaviour and attitudes: estimating the reliability of the use of the Amsterdam attitudes and communication scale through generalisability coefficients. Patient Educ. Couns. 45, 35-42.

De Haes, J.C., Oort, F.J., Hulsman, R.L., 2005. Summative assessment of medical students' communication skills and professional attitudes through observation in clinical practice. Med. Teach. 27, 583-589.

Grewen, K.M., Anderson, B.J., Girdler, S.S., Light, K.C., 2003. Warm partner contact is related to lower cardiovascular reactivity. Behav. Med. 29, 123-130.

Hedeker, D., Gibbons, R.D., 2006. Longitudinal Data Analysis. WileyInterscience.

Hellhammer, J., Fries, E., Schweisthal, O.W., Schlotz, W., Stone, A.A., Hagemann, D., 2007. Several daily measurements are necessary to reliably assess the cortisol rise after awakening: state- and trait components. Psychoneuroendocrinology 32, $80-86$. 
Kirschbaum, C., Hellhammer, D.H., 1994. Salivary cortisol in psychoneuroendocrine research: recent developments and applications. Psychoneuroendocrinology 19, 313-333.

Kudielka, B.M., Kirschbaum, C., 2005. Sex differences in HPA axis responses to stress: a review. Biol. Psychol. 69, 113-132.

Lee, S.J., Back, A.L., Block, S.D., Stewart, S.K., 2002. Enhancing physician-patient communication. Hematology (Am. Soc. Hematol. Educ. Program), 464483.

Malinow, K.L., Lynch, J.J., Foreman, P.J., Friedmann, E., Thomas, S.A., 1986. Blood pressure increases while signing in a deaf population. Psychosom. Med. 48, 95-101.

Marvel, K., Major, G., Jones, K., Pfaffly, C., 2000. Dialogues in the exam room: medical interviewing by resident family physicians. Fam. Med. 32, 628-632.

Meeuwesen, L., Bensing, J., Van den Brink-Muinen, A., 2002. Communicating fatigue in general practice and the role of gender. Patient Educ. Couns. 48, 233-242.

Phillips, A.C., Carroll, D., Ring, C., Sweeting, H., West, P., 2005. Life events and acute cardiovascular reactions to mental stress: a cohort study. Psychosom. Med. 67, 384-392.

Roter, D., 2002. The Roter Method of Interaction Process Analysis. The Johns Hopkins University, Baltimore, MD.

Roter, D., Larson, S., 2002. The Roter interaction analysis system (RIAS): utility and flexibility for analysis of medical interactions. Patient Educ. Couns. 46, 243-251.

Roter, D.L., Frankel, R.M., Hall, J.A., Sluyter, D., 2006. The expression of emotion through nonverbal behaviour in medical visits. J. Gen. Intern. Med. 21, S28-S34.

Schlotz, W., Schulz, P., Hellhammer, J., Stone, A.A., Hellhammer, D.H., 2006. Trait anxiety moderates the impact of performance pressure on salivary cortisol in everyday life. Psychoneuroendocrinology 31, 459-472.

Spielberger, C.D., 1983. State-Trait Anxiety Inventory (Form Y). Mind Garden, Redwood City, CA.

Steptoe, A., Fieldman, G., Evans, O., Perry, L., 1996. Cardiovascular risk and responsivity to mental stress: the influence of age, gender and risk factors. J. Cardiovasc. Risk 3, 83-93.

Ten Cate, Th.J., De Haes, J.C.J.M., 2000. Summative assessment of medical students in the affective domain. Med. Teach. 22, 40-43.

Van den Brink-Muinen, A., Van Dulmen, S., Messerli-Rohrbach, V., Bensing, J., 2002. Do gender-dyads have different communication patterns? A comparative study in Western-European general practices. Patient Educ. Couns. 48, 253-264.

Van den Brink-Muinen, A., Van Dulmen, A.M., Schellevis, F.G., Bensing, J.M. (Eds.), 2004. Second Dutch National Survey of General Practice. Focus on Communication: DoctorPatient Communication in the Netherlands. NIVEL, Utrecht (in Dutch).

Wahlqvist, M., Matsson, B., Dahlgren, G., Hartwig-Ericsson, M., Henriques, B., Hamark, B., Hösterey-Ugander, U., 2005. Instrumental strategy: a stage in students' consultation skills training? Scand. J. Prim. Health Care 23, 164-170.

Wust, S., Wolf, J., Hellhammer, D., Federenko, I., Schommer, N., Kirschbaum, K., 2000. The cortisol awakening response-normal values and confounds. Noise Health 7, 77-85.

Yerkes, R.M., Dodson, J.D., 1908. The relation of strength of stimulus to rapidity of habit formation. J. Comp. Neurol. Psychol. 18, 459-482. 